\title{
K-ordered Hamiltonian Graphs
}

Silviya Manesh

Department of Mathematics, Bharath University, Selaiyur, Chennai-600 073, India; Silvya.manesh@yahoo.com

\section{Abstract}

In this chapter, we review the following results proved in ${ }^{1,2,3,4}$ : (i) For $k \geq 3$, every ( $k+1$ )-Hamiltonian-connected graph is k-ordered. Determine $f(k, n)$ if $n$ is sufficiently large in terms of $k$. Let $g(k, n)=n / 2+k / 2-1$ (ii) $f(k, n)=g(k, n)$ if $n \geq 1$ lk-3

(iii) $\mathrm{f}(\mathrm{k}, \mathrm{n}) \geq \mathrm{g}(\mathrm{k}, \mathrm{n})$ for any $\mathrm{n} \geq 2 \mathrm{k}$ and $\mathrm{f}(\mathrm{k}, \mathrm{n})>\mathrm{g}(\mathrm{k}, \mathrm{n})$ if $2 \mathrm{k} \leq \mathrm{n} \leq 3 \mathrm{k}-6$ (iv) if $\mathrm{G}$ is a graph of order $\mathrm{n}$ with $3 \leq \mathrm{k} \leq \mathrm{n} / 2$ and $\operatorname{deg}(\mathrm{u})+\mathrm{deg}$ (v) $\geq n+(3 k-9) / 2$ for every pair $u, v$ of non-adjacent vertices of G, then $G$ is k-ordered Hamiltonian.

Keywords: Adjacency, Connectedness, Hamilton, Vertices

\section{Introduction}

In this section, the concept of K-Hamiltonian connected graphs is introduced. The result is that, for $\mathrm{k} \geq 3$, every $(\mathrm{k}+1)$-hamiltonian connected graph is $\mathrm{k}$-ordered is established. Also, necessary and sufficient conditions for a graph to be k-ordered are discussed. The notations used are recalled here. We write v1, (x1), v2, (x2), .., vk-1, (xk-1), vk to indicate a v1-vk path that contains the k vertices v1, v2 ...vk, and possibly upto k-1 additional vertices, namely $\mathrm{x} 1, \mathrm{x} 2, \ldots \mathrm{xk}-1$. Thus, for $1 \leq \mathrm{j} \leq \mathrm{k}-1,(\mathrm{x} 1)$ indicates that some vertex, which we denote by xi, may (or) may not be present on the path. So, for each $\mathrm{i}(1 \leq \mathrm{i} \leq \mathrm{k}-1)$, the vertices $v 1$ and vi+1 are either adjacent or vi, vi+1 is a path. For example, u, v (x), y indicates the path $\mathrm{u}, \mathrm{v}, \mathrm{y}$ or the path $\mathrm{u}, \mathrm{v}, \mathrm{x}, \mathrm{y}$.

Proposition 1.1: Let $G$ be a Hamiltonian graph of order $\mathrm{n} \geq 3$. If $\mathrm{G}$ is $\mathrm{k}$-ordered, $3 \leq \mathrm{k} \leq \mathrm{n}$, then $\mathrm{G}$ is (k-1)connected.

Proof: Suppose, to the contract that $\mathrm{G}$ is not (k-1) connected. Then, there exists a cut set $S=\mathrm{v}_{1}, \mathrm{v}_{2}, \ldots, \mathrm{v}$ of $\mathrm{G}$, where $\leq \mathrm{k}-2$. Let $\mathrm{v}_{+1}$ and $\mathrm{v}_{+2}$ be vertices belonging to distict components of G-S. Consequently, every $\mathrm{v}_{+1}-\mathrm{v}_{+2}$ path in $G$ contains vertices of $S$, so $G$ contains no Hamiltonian cycle containing the vertices of the sequence $\mathrm{v}_{1}, \mathrm{v}_{2} \ldots, \mathrm{V}$, $\mathrm{v}_{+1}, \mathrm{v}_{+2}$ in this order. Hence $\mathrm{G}$ is not $(+2)$-ordered and so is not k-ordered.

Corollary 1.2: If $G$ is a k-ordered Hamiltonian graph, then $\delta(G) \geq k-1$.
Sufficient conditions for k-ordered graphs

Many sufficient conditions have been given for Hamiltonian graphs. Two of the best known are by Dirac and Ore.

Theorem 1.3 (Dirac): Let $G$ be a graph of order $n \geq 3$. If $\operatorname{deg} v \geq n / 2$ for every vertex $v$ of $G$, then $G$ is Hamiltonian.

TheOrem 1.4 (ORE): Let $G$ be a graph of order $n \geq 3$. If for every pair $\mathrm{u}, \mathrm{v}$ of non-adjacent vertices of $\mathrm{G}$, deg $\mathrm{u}+\operatorname{deg} \mathrm{v}$ $\geq \mathrm{n}$, then $\mathrm{G}$ is hamiltonian.

LEMMA 1.5: Let $G$ be a graph of order $n \geq 3$ and let $S: v_{1}, v_{2}$, $\ldots, v_{k}$ be a sequence of $k$ distinct vertices of $G$, where 3 $\leq \mathrm{k} \leq \mathrm{n}$. If

$$
\operatorname{deg} \mathrm{u}+\operatorname{deg} \mathrm{v} \geq \mathrm{n}+2 \mathrm{k}-7
$$

For every pair $\mathrm{u}, \mathrm{v}$ of non adjacent vertices of $\mathrm{G}$, then $G$ contains a $v_{1}-v_{k}$ path of the type $v_{1},\left(x_{1}\right), v_{2},\left(x_{2}\right), \ldots$ $\left(\mathrm{x}_{\mathrm{k}-1}\right), \mathrm{v}_{\mathrm{k}}$ or a $\mathrm{v}_{\mathrm{k}}-\mathrm{v}_{\mathrm{k}-1}$ path of the type $\mathrm{v}_{\mathrm{k}}, \mathrm{v}_{1},\left(\mathrm{x}_{1}\right), \mathrm{v}_{2}$, $\left(\mathrm{x}_{2}\right), \ldots,\left(\mathrm{x}_{\mathrm{k}-2}\right), \mathrm{v}_{\mathrm{k}-1}$.

Proof: Consider the vertices $\mathrm{v}_{1}$ and $\mathrm{v}_{2}$. If $\mathrm{v}_{1}$ and $\mathrm{v}_{2}$ are adjacent, then $G$ contains the path $\mathrm{v}_{1}$,vs:; otherwise, deg $\mathrm{v}_{1}+\operatorname{deg} \mathrm{v}_{2} \geq \mathrm{n}+2 \mathrm{k}-7 \geq \mathrm{n}-1$, which implies the existence of a vertex $\mathrm{x} 1$ mutually adjacent to $\mathrm{v}_{1}$ and $\mathrm{v}_{2}$ and so $\mathrm{v}_{1}, \mathrm{x}_{1}, \mathrm{v}_{2}$ is a path in $\mathrm{G}$. In any case, $\mathrm{G}$ contains a path $\mathrm{v}_{1},\left(\mathrm{x}_{1}\right), \mathrm{v}_{2}$. Now, consider the vertex $v_{3}$. If $v_{2} v_{3} \in E(G)$, then $G$ contains the path $\mathrm{v}_{1},\left(\mathrm{x}_{1}\right), \mathrm{v}_{2}, \mathrm{v}_{3}$. Suppose, then that $\mathrm{v}_{2} \mathrm{v}_{2} \in \mathrm{E}(\mathrm{G})$. Thus, $\operatorname{deg} v_{2}+\operatorname{deg} v_{2} \geq n+2 k-7$ by hypothesis. Since $G$ has 
order $\mathrm{n}$, the vertices $\mathrm{v}_{2}$ and $\mathrm{v}_{3}$ are mutually adjacent to at least $2 k-5$ vertices. if $k \geq 4$, then $G$ contains a vertex $x_{2}$ distinct from $\mathrm{v}_{1}$ and $\mathrm{x}_{1}$ (if it exists) such that $\mathrm{x}_{2}$ is mutually adjacent to $v_{2}$ and $v_{3}$. Hence $G$ contains the path $v_{1},\left(x_{1}\right)$, $\mathrm{v}_{2},\left(\mathrm{x}_{2}\right), \mathrm{v}_{3}$. Suppose, then that $\mathrm{k}=3$ and that $\mathrm{G}$ contains to vertex distinct from $\mathrm{v} 1$ and $\mathrm{x} 1$ that is mutually adjacent to $\mathrm{v}_{2}$ and $\mathrm{v}_{3}$. If $\mathrm{v}_{3}$ is adjacent to $\mathrm{v}_{1}$, then $\mathrm{v}_{3}, \mathrm{v}_{1},\left(\mathrm{x}_{1}\right), \mathrm{v}_{2}$ is a path of $\mathrm{G}$. If $\mathrm{v}_{3}$ is not adjacent to $\mathrm{v}_{1}$, then $\mathrm{v}_{2}$ and $\mathrm{v}_{3}$ are mutually adjacent to 1 and to no other vertex, while $\mathrm{v}_{2}$ is adjacent to $\mathrm{v}_{1}$. However, then $\mathrm{v}_{1}, \mathrm{v}_{2}, \mathrm{x}_{1}, \mathrm{v}_{3}$ is a path in $\mathrm{G}$.

Proceeding inductively, assume that we have constructed a path $\mathrm{v}_{1},\left(\mathrm{x}_{1}\right), \mathrm{v}_{2},\left(\mathrm{x}_{2}\right), \ldots,\left(\mathrm{x}_{\mathrm{j}-2}\right), \mathrm{v}_{\mathrm{j}-1}$ in G. Suppose first that $j \leq k-1$. It is to show that $G$ contains a path $v_{1}, \ldots$, $\left(\mathrm{x}_{1}\right) \mathrm{v}_{2}\left(\mathrm{x}_{2}\right) \mathrm{v}_{\mathrm{j}}$. If $\mathrm{v}_{\mathrm{j}-1}$ is adjacent to $\mathrm{v}_{\mathrm{j}}$. If $\mathrm{v}_{\mathrm{j}-1}$ is adjacent to $\mathrm{v}_{\mathrm{j}}$, then $G$ contains such a path. Suppose then that $v_{j-1} v_{j} \in$ $\mathrm{E}(\mathrm{G})$. If $\mathrm{G}$ contains a vertex $\mathrm{x}_{\mathrm{j}-1}$ distinct from the vertices on the path $\mathrm{v}_{1},\left(\mathrm{x}_{1}\right), \mathrm{v}_{2},\left(\mathrm{x}_{2}\right), \ldots,\left(\mathrm{x}_{\mathrm{i}-2}\right)$ such that $\mathrm{x}_{\mathrm{j}-1}$ is mutually adjacent to $v_{j-1}$ and $v_{j}$, then $G$ contains a path of the designed type, otherwise $v_{j-1}$ and $v_{j}$ are mutually adjacent to at most $2_{j-4}$ vertices and $G$ contains at least $n+2 k-2_{j-1}$ vertices. Since $k \geq j+1$, this produces a contradiction, and hence the desired claim is verified.

Finally, suppose that $j=k$, that is, assume that there is a path $\mathrm{v}_{1},\left(\mathrm{x}_{1}\right), \mathrm{v}_{2},\left(\mathrm{x}_{2}\right), \ldots,\left(\mathrm{x}_{\mathrm{k}-2}\right), \mathrm{v}_{\mathrm{k}-1}$ is constructed in G. It is to show that $\mathrm{G}$ contains either a path $\mathrm{v}_{1},\left(\mathrm{x}_{1}\right), \mathrm{v}_{2},\left(\mathrm{x}_{2}\right), \ldots$, $\mathrm{v}_{\mathrm{k}-1},\left(\mathrm{x}_{\mathrm{k}-1}\right), \mathrm{v}_{\mathrm{k}}$ or a path $\mathrm{v}_{\mathrm{k}}, \mathrm{v}_{1},\left(\mathrm{x}_{1}\right), \mathrm{v}_{2},\left(\mathrm{x}_{2}\right) \ldots,\left(\mathrm{x}_{\mathrm{k}-2}\right), \mathrm{v}_{\mathrm{k}-1}$. If either $\mathrm{v}_{\mathrm{k}} \mathrm{v}_{\mathrm{k}-1} \in \mathrm{E}(\mathrm{G})$ or $\mathrm{v}_{\mathrm{k}} \mathrm{v}_{1} \in \mathrm{E}(\mathrm{G})$, then the desired result is obtained, thus assume that $\mathrm{v}_{\mathrm{k}}$ is adjacent to neither $\mathrm{v}_{\mathrm{k}-1}$ nor $\mathrm{v}_{1}$. Also, if $\mathrm{v}_{\mathrm{k}-1}$ and $\mathrm{vk}$ are mutually adjacent to some vertex other than the (at most) $2_{\mathrm{k}-5}$ vertices on the path $\left(\mathrm{x}_{1}\right), \mathrm{v}_{2}$, $\left(\mathrm{x}_{2}\right), \ldots, \mathrm{v}_{\mathrm{k}-2},\left(\mathrm{x}_{\mathrm{k}-2}\right)$, the proof is complete; so assume that this is not the case. Hence $v_{k-1}$ and $v_{k}$ are mutually adjacent to at most $2_{\mathrm{k}-5}$ vertices. Since $\mathrm{G}$ has order $\mathrm{n}$, it follows that $\mathrm{v}_{\mathrm{k}-1}$ and $\mathrm{v}_{\mathrm{k}}$ are mutually adjacent to exactly $2_{\mathrm{k}-5}$ vertices (so all of the vertices $\mathrm{x}_{1}, \mathrm{x}_{2}, \ldots, \mathrm{x}_{\mathrm{k}-2}$ exist), and every other vertex of $\mathrm{G}$ is adjacent to exactly one of $\mathrm{v}_{\mathrm{k}-\mathrm{1}}$, and $\mathrm{G}$ contains the path $\mathrm{v}_{1}, \mathrm{x}_{1}, \mathrm{v}_{2}, \mathrm{x}_{2}, \ldots, \mathrm{v}_{\mathrm{k}-2}, \mathrm{x}_{\mathrm{k}-2}, \mathrm{v}_{\mathrm{k}}$, producing the desired path. Hence, the result.

\section{References}

1. Oberly DJ, Summer DP. Every connected, locally connected non trivial graph with no induced claw is Hamiltonian. J Graph Theory. 1979; 3(4):351-56.

2. Harary F, Nash-Williams C St. JA. On Eulerian and Hamiltonian graphs and line graphs. Canad Math Bull. 1965; 8:701-09.

3. Li M. On pancyclic claw-free graphs. Ars Combin. 1998; 50:279-91.

4. Ryjacek Z. Hamiltonian circuits in N2-locally connected k1,3-free graphs. J Graph Theory. 1990; 14:321-31. 